\title{
A exploração de uma Arquitetura Pedagógica em sala de aula
}

\author{
Geancarlo Zanattta (UFRGS) \\ Cassia Moraes (UFRGS) \\ Eduardo Zimmer (UFRGS) \\ Lucas Ewald (UFRGS) \\ Letícia Pettenuzzo (UFRGS) \\ Christianne Salbego (UFRGS) \\ Vera Maria Treis Trindade (UFRGS)
}

\begin{abstract}
Resumo. Este artigo é resultado de uma pesquisa exploratória realizada a partir da proposta de uma arquitetura pedagógica. Essa arquitetura configurou a prática em sala de aula e foi realizada com 120 alunos do ensino básico em uma escola de Porto Alegre. Sua aplicação junto aos alunos resultou em: (1) dedicação intensiva que ultrapassou o tempo da sala de aula; (2) interesse ampliado por criar disponibilidade para a aprendizagem; (3) aprendizagem maximizada. A arquitetura pedagógica proposta encontrou os desejos de nativos digitais que tem prazer em trabalhar com a web e ousadia para aprender e recriar conhecimentos.
\end{abstract}

\section{As possibilidades da Web 2.0}

Ambientes virtuais que antes exigiam um software específico e muitas vezes conhecimentos de programação, hoje podem ser estruturados por qualquer sujeito que tenha acesso a rede mundial de computadores, desde que seja um nativo ou imigrante confortável nesse mundo digital. De acordo com Prensky (2001) "nossos alunos hoje são todos os falantes "nativos" da linguagem digital dos computadores, vídeo games e da Internet." O conceito de Web 2.0 traz uma nova posição para os usuários, esse conceito apresenta em sua proposta diferentes possibilidades de interação online, colocando os sujeitos em uma posição de produtores de informação através de ambientes virtuais.

O que antes era publicado virtualmente apenas com a finalidade de consulta ou pesquisa, hoje é compartilhado como um convite à interação, à colaboração e à construção. A ideia da Web 2.0 rompe paradigmas, deslocando o usuário de uma posição de simples consumidor para agente participativo, responsável e proativo na construção coletiva de conhecimento. Ambientes como Pbworks, Blogs, Orkut, Twitter, Ning, Facebook e outras redes sociais na web são verdadeiros convites à liberdade de expressão, à autonomia e à interação. Essas ferramentas têm em suas características muito mais do que entretenimento, pois possibilitam a exposição de ideias, conceitos e pensamentos, resultantes das intervenções de diversos usuários online.

As possibilidades das diferentes ferramentas disponíveis na rede são empolgantes, envolventes e contagiantes. Seu uso não está limitado a grupos pequenos de usuários de algumas determinadas regiões, ao contrário, seu uso é aberto para a constituição de inúmeros grupos em escala mundial. Com essa potencialidade de utilização os usuários são capturados como agentes que assim vão transformando o perfil e conceito da Web 2.0. Para O'Reilly (2006) a "Web 2.0 é a mudança para uma 
internet como plataforma, e um entendimento das regras para obter sucesso nesta nova plataforma. Entre outras, a regra mais importante é desenvolver aplicativos que aproveitem os efeitos de rede para se tornarem melhores quanto mais são usados pelas pessoas, aproveitando a inteligência coletiva."

Considerando as possibilidades de utilização dos recursos da web podemos visualizar um potencial como elemento para a construção de arquiteturas pedagógicas, pois este não fica limitado a ferramentas prontas (fechadas). As arquiteturas pedagógicas pressupõem a unificação de elementos para atender as necessidades de aprendizagens, contribuindo para que o usuário construa, colabore, registre e interaja. Dessa relação com os outros, facilitada pela telemática, é que se pode esperar um redimensionamento na produção intelectual. Isso requer a troca de informações e microformações interpares e entre diferentes usuários, na qual se exponencia a aprendizagem quando um aprende com o outro e todos aprendem juntos.

Para abordagem didática na escola a Web 2.0 traz uma nova estrutura e organização, em especial para os laboratórios de informática, pois não são requeridos somente os softwares de autoria que geralmente têm suas licenças com custo financeiro elevado. Utilizando a Internet os professores podem planejar arquiteturas pedagógicas que contemplem produções feitas pelos alunos com o auxílio de ferramentas para elaboração de vídeos, apresentações, histórias em quadrinhos, textos colaborativos, criação de Home Pages e outros, feitos de maneira rápida, simples e online, estruturando estratégias que proporcionem as aprendizagens não só dos alunos, mas também do professor.

Uma proposta de arquitetura pedagógica que traz a Web 2.0 como um dos elementos exige uma postura desafiadora do professor, não exigindo de si mesmo domínio total do recurso para ensinar. A ideia é que os alunos sejam envolvidos a descobrir e construir juntos, assim aprender uns com os outros alunos/alunos e alunos/professores.

Ao trabalhar com arquiteturas pedagógicas que contemplam os recursos da Web 2.0, o professor proporciona aos seus alunos a mesma linguagem que eles, nativos digitais, estão acostumados. Seu aprendizado é da ordem do fractal. Aqui as observações de [Veen e Vrakking 2009, p. 35] sobre a natureza dessa aprendizagem mostram que:

[...] "a diferença entre o Homo Zappiens e você é que você funciona linearmente, lendo primeiro as instruções - usando o papel - e depois começa a jogar, descobrindo as coisas por conta própria quando há problemas. O Homo Zappiens não usa a linearidade, ele primeiro começa a jogar e, depois, caso encontre problemas, liga para um amigo, busca informação na internet ou envia uma mensagem para um fórum. Em vez de trabalhar sozinho ele usa redes humanas e técnicas quando precisam de respostas instantâneas."

É com esta perspectiva em mente que desenvolvemos o trabalho com as arquiteturas pedagógicas com alunos das $5^{\mathrm{a}}$ e $6^{\mathrm{a}}$ séries do ensino fundamental, como se verá na sessão 3 (A arquiteturas pedagógicas em sala de aula), mas antes disso convém ampliar a compreensão sobre as arquiteturas pedagógicas na sua interface com a posição de professores e alunos-nativos digitais. 


\section{A proposta de Arquiteturas Pedagógicas}

Nossos alunos são nativos digitais, fazem parte da geração instantânea e exercem domínio sobre os recursos tecnológicos com significativa facilidade. Conectados à Internet passam literalmente pelo processo de virtualização, pois não estão simplesmente em frente ao computador; eles estão sobretudo em diversos outros espaços virtuais. Jovens e crianças contemporâneos ampliam sua rede social no 'mundo real' e no 'mundo digital'. Transitam nesses mundos sem dificuldade. Sua performance engloba 'tudo agora e ao mesmo tempo': ouvir música, assistir TV, conversar num chat, atualizar o perfil em sua rede social na web, escrever no caderno e etc. Frente à avalanche de inovações tecnológicas a escola continua muitas vezes limitada a ensinar no espaço da sala de aula, utilizando o quadro negro e o giz. Os recursos mais sofisticados, quando as escolas dispõem, são o vídeo e o retroprojetor.

A ideia nesse artigo é mostrar uma das diversas possibilidades que as tecnologias oferecem para as inovações nas práticas docentes. Compartilharemos a experiência vivenciada com alunos do ensino básico em um trabalho embasado na proposta de arquiteturas pedagógicas. Antes de prosseguirmos convém esclarecer o significado de arquiteturas pedagógicas com o qual desenvolvemos o trabalho na escola.

O conceito de arquiteturas pedagógicas que iremos abordar está de acordo com a percepção de [Carvalho, Nevado e Menezes, 2007, p. 39], que entendem por arquitetura:

"As arquiteturas pedagógicas são, antes de tudo, estruturas de aprendizagem realizadas a partir da confluência de diferentes componentes: abordagem pedagógica, software educacional, internet, inteligência artificial, Educação a Distância, concepção de tempo e espaço. O caráter dessas arquiteturas pedagógicas é pensar a aprendizagem como um trabalho artesanal, construído na vivência de experiências e na demanda de ação, interação e meta-reflexão do sujeito sobre os fatos, os objetos e o meio ambiente socioecológico. Seus pressupostos curriculares compreendem pedagogias abertas capazes de acolher didáticas flexíveis, maleáveis, adaptáveis a diferentes enfoques temáticos."

Um dos fatores que move a aprendizagem é o desejo do aluno em querer aprender, desejar respostas e desvendar dúvidas. Partimos da proposta de que para trabalhar com as tecnologias educacionais precisamos despertar o interesse dos alunos, envolvendo-os de acordo com suas realidades recheadas de novas linguagens e possibilidades de comunicação.

Hoje mais do nunca é necessário estar aberto às novas possibilidades e romper com o paradigma de que o professor deve saber tudo para ensinar, ou seja, o professor não precisa ter total domínio tecnológico para fazer uso de tais recursos em suas aulas. A posição do professor sofreu alterações, assim como também a posição do aluno. $\mathrm{O}$ processo de aprendizagem mudou, existe uma diferença na forma como aprendemos e na forma como essa geração aprende. Muitos professores ainda pensam e agem de forma linear ao planejar e realizar tudo por etapas. Nós, os professores, somos imigrantes nesse contexto digital. Já essa nova geração pensa e age de forma fractal, onde a forma de comunicação hipertextual se torna uma rede de informações na qual essa nova geração vai tecendo seus conhecimentos sem pré-definir um caminho para ser percorrido, o que não quer dizer que não tenha uma lógica. Para a geração Homo 
Zappiens a diferença reside em que não existe uma possibilidade única para se aprender e sim diferentes possibilidades. Cada sujeito organiza a sua aprendizagem ao construir a sua rede de trocas, de amigos e de convivências virtual. Com isso descortinam-se possibilidades para conhecer e aprender; é o que exploraremos adiante ao mostrar o desenvolvimento de arquiteturas pedagógicas em sala de aula.

Hoje, professores e alunos são demandados a serem cooperadores um com o outro; o professor assume o papel de ser o provocador do saber e deixa de fornecer as respostas para fazer surgir às perguntas. São as perguntas que instigarão os alunos na busca por respostas. O aluno, por sua vez, assume um papel de autonomia, certamente guiada e orientada, que o instiga a ser responsável pela sua aprendizagem e, portanto, cooperador da construção do conhecimento. No entanto, esse reposicionamento das figuras e dos modos de ser do professor e do aluno só terá êxito se for aberto espaço para inovações metodológicas, ou seja, é necessário repensar o que, como e para que ensinar, atentando sempre para quem é o sujeito que temos em aula, saber que a proposta de trabalhar com as arquiteturas pedagógicas não é utilizar os recursos digitais por si mesmo, mas utilizar os recursos digitais como uma organização para se vislumbrar as estratégias pedagógicas que serão significativas, ou seja, é pensar que recursos serão válidos serem utilizados, com quais finalidades e que necessidades serão atendidas.

O currículo da sala de aula tradicional se assenta, prioritariamente, no material didático impresso que define o que e como ensinar [Apple e Christian-Smith, 1991; Moreira, 2001]. Igualmente inúmeros programas destinados à área educacional reproduzem as mesmas agendas prescritivas contidas nos livros didáticos. Têm-se materiais mais sofisticados do ponto de vista tecnológico, entretanto suas fronteiras sobre o pedagógico encerram-se nos limites de concepções de ensino e não propriamente de aprendizagem. Tal conduta acomoda as práticas escolares e distanciam professores e estudantes de pensar e realizar aprendizagens.

A ideia em fazer uso das tecnologias na educação exige novas metodologias, não se trata apenas de saber usar o recurso, mas sim o que se pretende com eles, ou seja, não adianta deixar de escrever um texto no caderno para ir digitá-lo no laboratório de informática. De nada adianta o uso das tecnológicas se não existir metodologias para seu uso significativo. A aprendizagem ocorre nesta perspectiva quando desestabilizamos o aluno, retirando-o da inércia de ser consumidor passivo para ajudálo a assumir posturas ativas e propositivas ao participar da construção do conhecimento. Isso significa para o aluno a possibilidade de acesso a diferentes meios de informação para ser envolvido e provocado a desejar construir conhecimento. Isso é trabalhar com as arquiteturas pedagógicas.

As arquiteturas pedagógicas pressupõem a necessidade de olhar os recursos disponíveis no entorno dos sujeitos e propor estruturas de planejamento que constituam a rede social entre os alunos, possibilitando interações e construções de conhecimentos entre os sujeitos. Cada aluno tem sua participação e responsabilidade pelo aprender guiado pelos professores que, ao mesmo tempo, se constituem como sujeitos da contemporaneidade, em sintonia com os deveres dos nativos.

As arquiteturas pedagógicas são as organizações estruturantes de novos processos de aprendizagem, ou seja, é olhar ao redor para identificar as necessidades, os 
recursos e as ferramentas em potencial para um trabalho que provoque a aprendizagem através da interação e permita o desenvolvimento da capacidade de meta-reflexão e a construção da autonomia.

$\mathrm{O}$ trabalho com as arquiteturas pedagógicas exige da equipe envolvida uma postura de pensar frequentemente sobre as possibilidades que se apresentam com as tecnologias emergentes para inovar e qualificar os processos de aprendizagens. Ao pensar em arquiteturas pedagógicas, deve-se lembrar que a pedagogia demandará dispor os recursos, as ferramentas e as ideias disparadoras dos processos de aprendizagem, mas são as ações dos sujeitos que indicarão a forma de conduzir a proposta de trabalho.

Tendo em vista que o trabalho com as arquiteturas pedagógicas é estruturado a partir da confluência de diferentes componentes, trataremos mais especificamente sobre uma arquitetura pedagógica que teve como elemento as possibilidades da web 2.0 nas ações pedagógicas e o software de autoria Klik and Play.

\section{A arquitetura pedagógica em sala de aula}

A arquitetura pedagógica relatada aqui foi estruturada com a unificação de diferentes elementos, entre eles duas ferramentas da web (Blogs e Pbworks) e um software de autoria (Klik and Play). A combinação entre ferramentas disponíveis na Internet e o software de autoria surgiu da necessidade dos alunos diante do desafio de produzirem um jogo digital e registrarem o processo de construção em um ambiente colaborativo, ou seja, o software de autoria Klik and Play foi utilizado para produção de jogos e os ambientes Blogs e Pbworks para registros dessa produção.

Durante a disciplina de Arquiteturas Pedagógicas para EAD, do Programa de Pós-Graduação de Informática na Educação de uma Universidade de Porto Alegre foram apresentados aos alunos diferentes softwares, entre eles um em especial chamou a atenção por se tratar de uma ferramenta livre, que possibilita a construção de jogos digitais. O software apresentado Klik and Play foi um desafio aos alunos-professores presentes para trabalhar com uma arquitetura pedagógica em suas práticas docentes.

Aceito o desafio o primeiro passo foi identificar uma professora de disciplina com uma turma de alunos dispostos a explorar ambientes digitais desconhecidos. A segunda etapa foi planejar a arquitetura pedagógica para o trabalho de produção de jogos digitais, levando em consideração os interesses dos alunos, os recursos disponíveis e os objetivos que se pretendiam alcançar.

Ficou combinado que a realização do trabalho seria em parceria com a professora de História, nas turmas de $5^{\mathrm{a}}$ e $6^{\mathrm{a}}$ séries do ensino fundamental. A arquitetura pedagógica foi estruturada dentro do Blog para os alunos de $6^{a}$ série e dentro do Pbworks para os alunos de $5^{\mathrm{a}}$ série. A diferença de ambientes para a estruturação da arquitetura foi resultado da escolha de cada turma.

Dentro dos ambientes criados para cada arquitetura descrevemos a proposta de trabalho, os objetivos, os critérios para produção, os recursos que utilizaríamos e como seria registrado o processo de auto-avaliação do trabalho produzido. Aqui é importante destacar que antes de pensar em propor esse trabalho aos alunos a equipe pedagógica pensou quais os possíveis contribuições que o uso dos recursos digitais acrescentariam no processo de aprendizagem dos alunos, ou seja, nesse momento a equipe precisou 
levantar as informações do que queria ensinar, para que e quais as necessidades dos alunos para aprender, posto isso, então se passo para a etapa de elaborar estratégias para então propor ao alunos.

A proposta de produzir um jogo digital referente aos conteúdos da disciplina de História, veio da necessidade da professora em trazer mais próximo da realidade dos alunos os assuntos abordados. A arquitetura pedagógica previu a apropriação tecnológica interpares, pois as professoras não detinham o domínio das ferramentas da web. Isso implicou na disponibilidade das professoras em apostar num tipo de trabalho no qual seus alunos tinham a chance de criar por si, contando com a ajuda pontual delas e dos pares, desenvolvendo os objetos de aprendizagem. Esse desprendimento das professoras mostra uma fratura no paradigma da figuração do professor, ou seja, rompe com a ideia de que ele tão somente 'dá' aula quando domina por inteiro os conteúdos e as ferramentas.

Como o envolvimento dos alunos com a produção dos jogos foi além dos horários estabelecidos em grupo, muitos alunos optaram por baixar o software Klik and Play em suas máquinas residências para exercitarem, tirando dúvidas, fazendo testes e resolvendo problemas. Com isso os alunos necessitaram de um ambiente que serviu de diário, e para tal contemplou-se o uso do Blog e do Pbworks (ver Figura 1 e 2) que permitiu o registro do processo pelas equipes de trabalho ou individualmente. $\mathrm{O}$ objetivo disso foi fomentar a aprendizagem reflexiva. Os Blogs e os Pbworks serviram como ambientes de escrita coletiva ao mesmo tempo em que os alunos organizaram suas ideias sobre o que e como iriam fazer, realizando uma auto-avaliação sobre as etapas do trabalho. Nos registros dos alunos foi possível identificar o que aprenderam e como aprenderam. O Klik and Play além de servir para a produção dos jogos, que posteriormente seriam compartilhados na web, também serviu como criação dos próprios alunos de um objeto de aprendizagem, ou seja, um jogo digital. Mas não se tratava de produzir um jogo ou qualquer jogo. Era preciso usar o Klik and Play no contexto dos conteúdos de História.

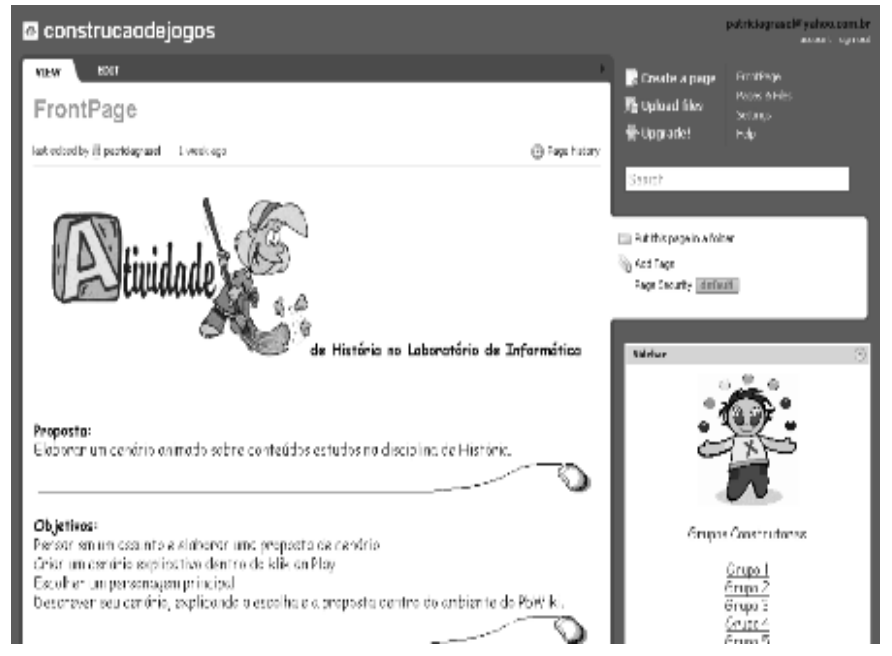

Figura 1 - Arquitetura Pedagógica no Pbworks 
O trabalho com a arquitetura utilizando o Pbworks para escrita colaborativa foi desenvolvido para aproximadamente 120 alunos de $5^{\mathrm{a}}$ série, na faixa etária de 10 a 12 anos. Os alunos organizados em grupos produziram o jogo digital sobre a pré-história e fizeram o registro de dificuldades, dúvidas, soluções de problemas, estratégias e descobertas em sua Page no Pbworks. (endereço http://construcaodejogos.pbwiki.com). Além do registro do processo os alunos também elaboraram uma ficha explicativa, justificando os personagens e cenários utilizados, além do tema abordado. Uma das estratégias de culminância foi à avaliação dos jogos pelos próprios alunos, onde cada grupo explorou o jogo desenvolvido pelos colegas, deixando registrado seu parecer na Page construída pelo grupo.

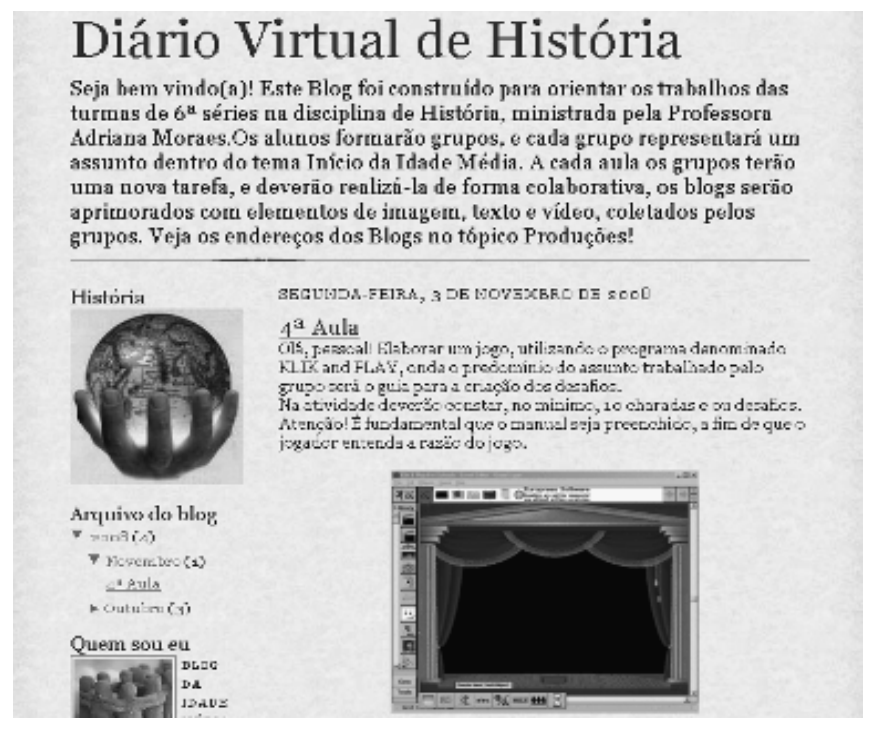

Figura 2 - Arquitetura Pedagógica no Blog

O segundo projeto desenvolvido com os alunos de $6^{\mathrm{a}}$ série surgiu da intenção de utilizar o software Klik and Play interligando-o com a exploração de Blogs (Figura 2). Foi organizado um Blog (endereço www.diariovirtualdehistoria.blogpost.com) como estratégia de orientação para os processos de trabalho dos alunos, uma das atividades proposta foi à organização de Blogs particulares para registros de suas descobertas. Os alunos deveriam criar, editar e alimentar o seu espaço virtual. Os grupos fizeram uso das diferentes mídias audiovisuais, pesquisas, coletas e produção na Internet. Para finalizar o trabalho os alunos foram desafiados a transformar em jogo digital a pesquisa realizada e registrada no seu Blog.

Nas duas propostas de trabalho foi possível perceber o envolvimento e interesse dos alunos as aprendizagens não ficaram limitadas apenas durante o processo de produção dos jogos, ao término da proposta de arquiteturas pedagógica os alunos continuaram envolvidos elaborando outros jogos, com outros temas e para outras disciplinas. A construção dos jogos foi além dos conteúdos curriculares da disciplina de História, os alunos demonstraram maior apropriação para compreender a temática da disciplina, que foi representada através de uma linguagem comum para eles nativos digitais. As aprendizagens foram além das paredes das salas de aulas, os alunos demonstraram autoconfiança, capazes de produzir jogos digitais que poderiam ser 
explorados por todos da turma, demonstraram melhora no relacionamento com os colegas, pela necessidade de trabalhar colaborativamente realizando os registros das dificuldades e encaminhamentos do grupo durante a realização do jogo. O envolvimento dos alunos com os recursos tecnológicos foi tão significativo que muitos se manifestaram para trabalhar voluntariamente no curso de inclusão digital para melhor idade (idosos) que a Escola ofereceu durante todo o ano letivo. Foi possível identificar que quando trabalhamos com arquiteturas pedagógicas que nascem das necessidades e interesses dos alunos eles revelam resultados significativos, possibilitamos aprendizagens além das grades curriculares e dos muros da escola. As aprendizagens agregam a responsabilidade social e a educação para formar um sujeito como um todo, contribuindo para preparar cidadãos para vida.

As arquiteturas pedagógicas, aliadas a abertura das professoras em trabalhar com a incerteza e ao reconhecimento dos nativos digitais, produziram efeitos sobre ambos os grupos que se materializou em: (1) dedicação intensiva que ultrapassou o tempo da sala de aula; (2) interesse ampliado por criar disponibilidade para a aprendizagem; (3) aprendizagem maximizada que envolveu: (a) a apropriação das ferramentas (blog, wiki e o klik and play); (b) o trabalho em grupo para além da sala de aula; (c) a solução de problemas; (d) a consulta e a confiança no conhecimento dos pares; (e) a combinação de mídias; (f) a pesquisa temática em História; (g) a tomada de decisões; (h) a produção de um objeto de aprendizagem reunindo todas as demandas colocadas pelas arquiteturas pedagógicas. Sobretudo, as arquiteturas pedagógicas encontraram os desejos de nativos digitais que tem prazer em trabalhar com a web e ousadia para aprender e recriar conhecimentos.

\section{Conclusão}

Hoje, não é mais necessário justificar a importância das ferramentas digitais na escola, pois já existe consenso quanto à sua contribuição no processo de aprendizagem. Entretanto, é necessário estar atento à forma de exploração das tecnologias nos espaços educativos. A exploração das ferramentas digitais requer a formação, o envolvimento e o compromisso não apenas do professor, mas de toda equipe pedagógica envolvida, incluindo o aluno. Nesse sentido, é importante repensar quais são os reais desejos em fazer uso dos Blogs, Pbworks e jogos digitais. A proposta de trabalho com arquiteturas pedagógicas vai além da união de ferramentas, pois contempla a intenção pedagógica do que se deseja com o uso de tais ferramentais. Trata-se de usar as ferramentas para qualificar o processo.

Muito mais que a simples utilização, por modismo ou por considerar novidade é importante destacar a intenção pedagógica em organizar arquiteturas que contemplem o uso da web, ou seja, o educador ao aderir ao trabalho com arquiteturas pedagógicas transforma-se em um estimulador da curiosidade do aluno, pois passa a ter um olhar mais atento para as possibilidades de aprendizagens. Neste caso, a aula se torna interessante e motivadora, contribuindo para a participação do aluno e a produção do conhecimento, pois o aluno é a origem da arquitetura pedagógica.

As interações proporcionadas pelos ambientes das ferramentas da Web 2.0 qualificam a proposta das arquiteturas pedagógicas e nessa arquitetura prevalece $\mathrm{o}$ desafio de romper com a ideia de tempo circunscrito à escola para a aprendizagem. 
Nosso trabalho experimental com as arquiteturas pedagógicas mostrou que quando as tecnologias emergentes da Web 2.0 são incorporadas na aprendizagem, os alunos respondem prontamente e maximizam a aprendizagem. Isso ocorre porque nossos alunos lidam com as ferramentas digitais muito antes de seus professores pensarem em utilizá-las. Eles são nativos digitais e desejam que a escola e suas propostas correspondam ao que eles dispõem culturalmente: Internet, informação em abundância, familiaridade visceral com as tecnologias emergentes. Em razão de como funcionam as tecnologias emergentes ao solicitarem um alto nível de interação, nossos alunos já trazem como bagagem uma competência comunicativa precocemente desenvolvida se comparada com a geração de seus professores e de sua família.

Para os professores a emergência da web 2.0 coloca em xeque o paradigma da figuração professoral para desenvolver a habilidade de trabalhar com as incertezas e o desafio de criar arquiteturas pedagógicas instigantes.

\section{Referências}

APPLE, M.W. e CHRISTIAN-SMITH, L.K. (eds.) The politics of the textbook. New York: Routledged, 1991.

CARVALHO, Marie J. S., NEVADO, Rosane e MENEZES, Crediné S. (2007) "Aprendizagem em Rede na Educação a Distância - estudos e recursos para formação de professores." Lens - Porto Alegre/RS

PRENSKY, Marc. Digital Natives, Digital Immigrants From On the Horizon (MCB University Press, Vol. 9 No. 5, October 2001)

PRIMO, Alex. (2007) "Interação mediada por computador: comunicação, cibercultura, cognição." Sulina - Porto Alegre/RS.

PRIMO, Alex. (2007, V. 9, p. 1-2) “O aspecto relacional das interações na Web 2.0” ECompós - Brasília

O'REILlY, Tim. (2006) "Web 2.0 Compact Definition: Trying Again" (http://radar.oreilly.com/2006/12/web-20-compact-definition-tryi.html acessado em Outubro de 2009)

VEEN, Wim; WRAKKING, Ben. (2009) "Homo Zappiens: educando na era digital." Artmed - Porto Alegre/RS. 